\section{Joe Robjohns}

\section{HM Treasury (formerly of Office for National Statistics)}

\section{Damian Whittard}

\section{Office for National Statistics}

\title{
How similar are ONS's annual and monthly business inquiries?
}

T he Office for National Statistics (ONS) is responsible for producing different vintage estimates of gross domestic product (GDP). ${ }^{1}$ ONS publishes four revised estimates of GDP; the first estimate of GDP output is published around 25 days after the end of the quarter (Robinson 2005) while the second estimate is published four and a half weeks later. The Monthly Production Inquiry (MPI) and Monthly Inquiry into the Distribution and Service Sector (MIDSS) are used in the production of the preliminary estimates of GDP, before the Annual Business Inquiry

(ABI) is incorporated in the third estimate. The fourth estimate and first benchmark of GDP is published in the National Accounts Blue Book after a lag of approximately 18 months, although this estimate can be revised through stalled revisions or methodological changes (Mahajan 1997).

In order to ensure the quality of the GDP estimates and the data sources that go into producing them, ONS has implemented a programme of analysis to explore whether the data are subject to any bias. This article adds to the growing literature by comparing results from the MPI and MIDSS monthly surveys with the ABI annual survey. The article supports ONS's monthly and annual surveys' reconciliation programme started in 2000 and which was last completed for the release of the Blue Book 2005.

\section{Analysis methodology}

In order to assess the coherence between the monthly surveys and ABI turnover, a two-stage methodology was employed.
Firstly, an analysis of ONS's final aggregated estimate of monthly data was compared with the ABI annual series. This analysis is reported in levels and growth rates for both an unadjusted (raw data) series and an adjusted MPI/MIDSS series. Adjustments are in the main applied to manage survey design issues such as sample rotation and large reclassifications; this is done to help preserve a continuous time series of growth (Duff and Morgan 2007). The second stage uses ONS's Virtual Microdata Laboratory ${ }^{2}$ to analyse a business unit's monthly response with the same unit's annual response. The microdata sets were produced using a matching technique such that businesses are only maintained in the overlap if they represent a full year of monthly data that correspond to the same period recorded in the ABI. For example, a business reporting from April to March in the ABI but only from April to December in the monthly surveys would be dropped from the overlap. The results are presented using identical methodologies, but are reported for the MPI and MIDSS separately - a full description of MPI and MIDSS sectors with their corresponding Standard Industrial Classification (SIC) codes is listed in Appendix Table A1 and Table A2.

\section{MPI results}

Aggregate analysis

In this analysis, the published aggregate ABI data are used as the benchmark. The analysis is restricted to the years 1999 to 2005, as there were major differences in the sampling regime for the $\mathrm{ABI}$ before 
then (Jones 2000). The aggregate analysis explores the issue of bias in ABI and MPI turnover in terms of nominal levels and growth rates.

\section{Nominal values}

Table 1 records aggregate annual turnover for both the ABI and MPI and includes a ratio of MPI to $A B I$ turnover. A ratio of less than one indicates that the ABI turnover is higher than that for the MPI.

A key finding here is that there is a consistent underestimation of annual turnover in the MPI series compared with the ABI. This under-reporting is estimated to be more than 10 per cent of turnover in all of the seven years -73 per cent of this difference is attributed to two industries, 'food products, beverages' (SIC 15) and 'coke, refined petroleum products and nuclear fuel' (23). Of the two MPI series, adjusted MPI turnover is closer in terms of level of expenditure to the $\mathrm{ABI}$ series.

\section{Growth rates}

The level of turnover is important inasmuch as it provides a view of the economy at a particular point of time. However, of more importance is the growth rate, as it determines the long-term trend and indicates the strength within the sector as a whole. Figure 1 shows the growth rates of $\mathrm{ABI}$ and MPI turnover.

The MPI growth rates are closely aligned to those of the ABI for all data points. This suggests that the MPI shares the same statistical signal as the ABI and is unbiased. In five of the seven data points, the MPI adjusted growth rate is more closely aligned to the ABI series than the adjusted growth rate, although in three of these data points the difference is only marginal.

To assess the impact of individual industries on the aggregate position, Figure 2 decomposes the differences in the ABI and adjusted MPI turnover growth rate at the industrial level.

Table 1

$\mathrm{ABI}$ and $\mathrm{MPI}$ aggregate turnover

\begin{tabular}{lrrrrrr}
\hline & \multicolumn{2}{c}{ Turnover (f million) } & & \multicolumn{2}{c}{ Ratio (MPI/ABI) } \\
\cline { 2 - 3 } \cline { 6 - 7 } & ABI & $\begin{array}{r}\text { MPI } \\
\text { unadjusted }\end{array}$ & $\begin{array}{r}\text { MPI } \\
\text { adjusted }\end{array}$ & & $\begin{array}{r}\text { MPI } \\
\text { unadjusted }\end{array}$ & $\begin{array}{r}\text { MPI } \\
\text { adjusted }\end{array}$ \\
\hline 1999 & 461,771 & 395,350 & 412,066 & & 0.86 & 0.89 \\
2000 & 469,146 & 403,011 & 417,700 & & 0.86 & 0.89 \\
2001 & 461,898 & 393,911 & 409,270 & & 0.85 & 0.89 \\
2002 & 450,090 & 385,362 & 396,924 & & 0.86 & 0.88 \\
2003 & 447,637 & 389,232 & 398,825 & & 0.87 & 0.89 \\
2004 & 459,880 & 407,495 & 410,437 & & 0.89 & 0.89 \\
2005 & 466,731 & 413,013 & 414,269 & & 0.88 & 0.89 \\
\hline
\end{tabular}

Source: Author's calculation on ONS sources

\section{Figure 1}

Figure 2
There is no evidence of a systematic bias in any single industry. Figure 2 reports a counterbalancing effect: an inflated growth rate in one industry is offset by a deflated growth rate in another. 'Coke, refined petroleum products and nuclear fuel' (SIC 23) and 'motor vehicles, trailers and semi-trailers' (34) have the largest single differences of all the industries - they are the fifth and third largest industries in terms of output.

\section{Noise-to-signal ratio}

Table 2 expands the analysis of the congruence by comparing the unadjusted

\section{$\mathrm{MPI}$ and $\mathrm{ABI}$ annual turnover growth rates}

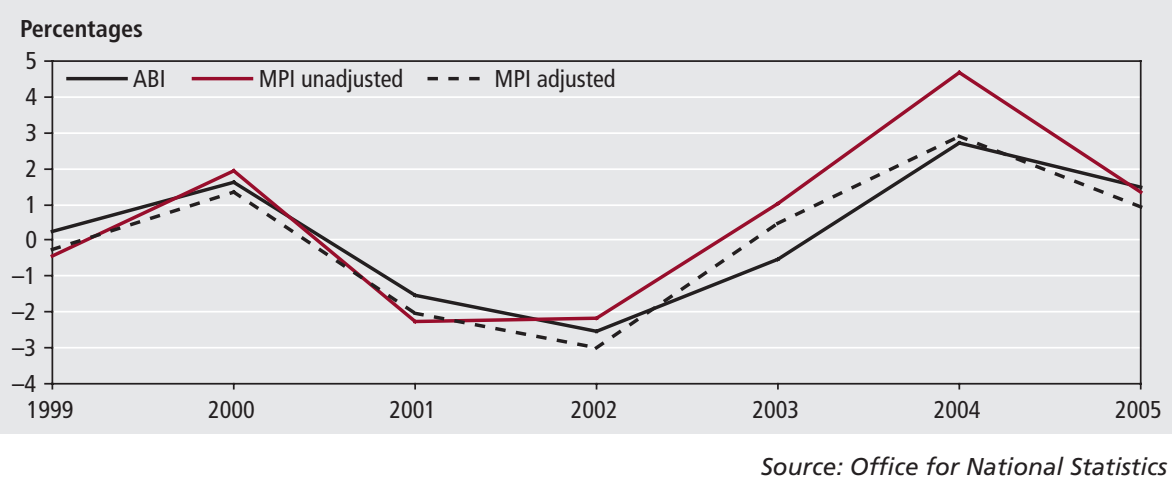

\section{Contributions to differences in $\mathrm{ABI}$ and adjusted MPI turnover growth rates}

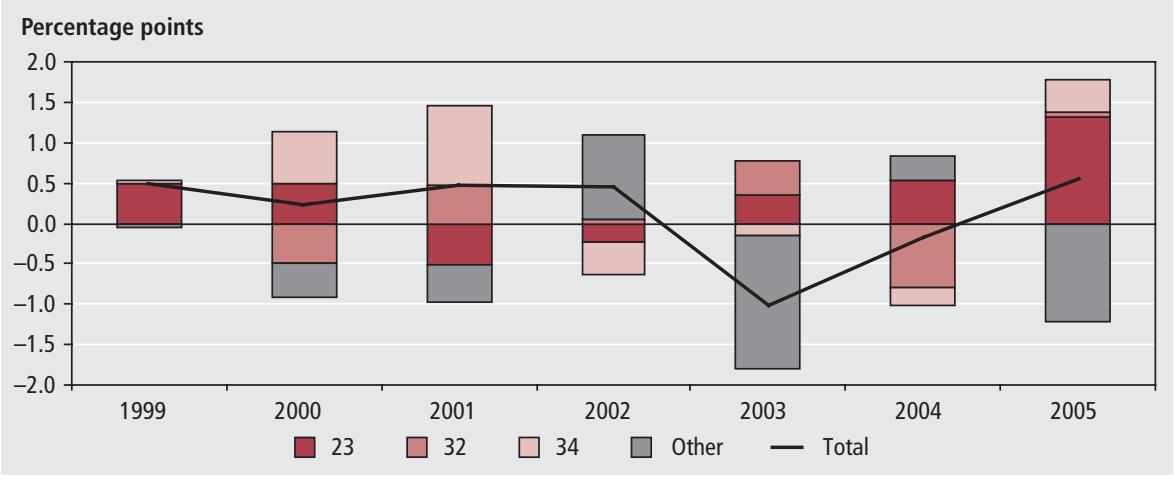

Source: Office for National Statistics

and adjusted noise-to-signal ratio. This is calculated by comparing the difference in the variation of MPI and ABI turnover growth rates with the variation of $\mathrm{ABI}$ turnover growth rates (see below) - the closer the ratio to zero, the greater the statistical signal.

MPI noise-to-signal ratio

$$
=\frac{\operatorname{var}\left(\frac{M P I^{t}-M P I^{t-1}}{M P I^{t-1}}\right)-\operatorname{var}\left(\frac{A B I^{t}-A B I^{t-1}}{A B I^{t-1}}\right)}{\operatorname{var}\left(\frac{A B I^{t}-A B I^{t-1}}{A B I^{t-1}}\right)}
$$

var variance

MPI MPI turnover

$A B I \quad$ ABI turnover

$\mathrm{t}$ time (year)

The ratios report a stronger signal in the adjusted series in terms of the manufacturing sector as a whole and also in the majority of two-digit SIC industries. The overall difference in variation is 0.54 points; however, this is considerably affected by the relatively poor performing industries of 'pulp, paper and paper products' (two-digit SIC20) and 'recycling' (37). At an industrial level, the adjusted series outperforms the unadjusted series in 12 of the 23 two-digit 
Table 2

Noise-to-signal ratio between the adjusted and unadjusted MPI time series and $A B I$ growth rates, 1999 to 2005

\begin{tabular}{|c|c|c|}
\hline SIC2 & Unadjusted & Adjusted \\
\hline 15 & 4.25 & 1.19 \\
\hline 16 & 0.94 & 1.04 \\
\hline 17 & 4.04 & 1.59 \\
\hline 18 & 1.83 & 1.78 \\
\hline 19 & -0.12 & -0.65 \\
\hline 20 & 9.46 & 1.97 \\
\hline 21 & -0.67 & -0.83 \\
\hline 22 & -0.66 & -0.79 \\
\hline 23 & 0.58 & 1.55 \\
\hline 24 & -0.45 & 0.59 \\
\hline 25 & 0.79 & -0.46 \\
\hline 26 & -0.88 & -0.79 \\
\hline 27 & -0.14 & -0.46 \\
\hline 28 & 3.30 & 0.89 \\
\hline 29 & 0.68 & 0.28 \\
\hline 30 & -0.20 & -0.48 \\
\hline 31 & 0.81 & 0.03 \\
\hline 32 & 0.11 & 0.42 \\
\hline 33 & 0.49 & 0.07 \\
\hline 34 & 2.54 & 3.13 \\
\hline 35 & 0.61 & 1.10 \\
\hline 36 & 3.08 & -0.57 \\
\hline 37 & 23.36 & 1.39 \\
\hline All industries & 0.70 & 0.16 \\
\hline
\end{tabular}

Source: Office for National Statistics

SIC industries; in six of the industries

$(15,17,20,28,36$ and 37$)$, the absolute differences are over two points. In 11 of the 23 two-digit SIC industrial categories, the unadjusted series outperforms the adjusted series. These 11 industries account for over 50 per cent of manufacturing turnover. In four of the industries $(19,23,34$ and 35), the unadjusted data outperforms the adjusted series by 0.5 or more points.

Overall, the results indicate that the adjusted series are more closely aligned to the $\mathrm{ABI}$ series in nominal levels, growth rates and the noise-to-signal ratio. However, the unadjusted series performs better in terms of turnover growth rates in two of the seven years and contains a greater statistical signal for 11 two-digit SIC industries which, combined, account for over 50 per cent of manufacturing output. This is an important finding of the research - if the ABI is taken as the benchmark, then the noise-to-signal ratio results suggest that adjusting the figures in themselves may not add value for certain industries.

As a result of ONS's research programme, a decision was recently made to revamp the Index of Production - ONS has now moved considerably away from adjustments, with most of the historical adjustments actually being removed. The findings from this article provide support for this change of approach, particularly at the industrial level.

The following analysis uses microdata to further explore the relationship between $\mathrm{ABI}$ and MPI returns, by analysing individual business responses.

\section{Microdata analysis}

This section considers the degree of fit between the reported turnover of the MPI and ABI surveys from individual businesses. The analysis uses formal measures of correlation and regression analysis. All analysis was completed using natural logarithms to 'normalise' the data, and hence improve its statistical properties.

Table 3 details the number of businesses that completed 12 months' worth of MPI returns and a matched annual ABI return, from 1999 to 2005 . Just 2 per cent $(150,000)$ of all manufacturing businesses, but onethird $(7,500)$ of all businesses included in the overall MPI sample, are included within the ABI/MPI matched sample. The 'moving target' nature of the MPI survey means that companies are only included in the matched sample if their monthly MPI returns directly correspond with the exact period of their ABI return.

As a deliberate part of the sampling strategy, the ABI and MPI samples are individually skewed towards large employers. Table $\mathbf{4}$ shows that a relatively low proportion of businesses are included in the sample, although they contribute a high percentage of total employment and, more often than not, turnover. With a relatively high proportion of sector employment included within the sample, it is possible to make inferences for the overall trend.

The coverage varies widely across industries. The largest two industries in terms of turnover, 'food products, beverages' (SIC 15) and 'chemical and chemical products' (24), are generally well covered in terms of both business count and employment. 'Fabricated metal products, except machinery and equipment' (28), which provides nearly 6 per cent of manufacturing output, however, is only covered in 1 per cent of businesses and 15 per cent of employment.

The ratios in Table 5 show that even when business units are matched directly, there is a consistent tendency to underestimate MPI turnover compared with $\mathrm{ABI}$ by over 15 per cent on average (2005 is an outlier attributable to 'coke, refined petroleum products and nuclear
Table 3

Frequencies of matched businesses in the overlap microdata set

\begin{tabular}{lrr}
\hline & $\begin{array}{r}\text { Frequency } \\
\text { (number) }\end{array}$ & Percentages \\
\hline 1999 & 3,417 & 2.0 \\
2000 & 3,290 & 2.0 \\
2001 & 3,227 & 2.0 \\
2002 & 3,060 & 1.9 \\
2003 & 2,909 & 1.9 \\
2004 & 2,938 & 1.9 \\
2005 & 2,696 & 1.8 \\
Total & 18,009 & \\
\hline
\end{tabular}

Source: Office for National Statistics

\section{Table 4}

Percentage of total business and employment contained in the overlap data set, 1999 to 2005

\begin{tabular}{|c|c|c|}
\hline & & Percentages \\
\hline SIC2 & Firm count & Employment \\
\hline 15 & 5 & 38 \\
\hline 16 & 23 & 53 \\
\hline 17 & 3 & 29 \\
\hline 18 & * & 21 \\
\hline 19 & * & 29 \\
\hline 20 & * & 16 \\
\hline 21 & 5 & 38 \\
\hline 22 & 1 & 30 \\
\hline 23 & 2 & 42 \\
\hline 24 & 8 & 55 \\
\hline 25 & 3 & 32 \\
\hline 26 & 3 & 46 \\
\hline 27 & 5 & 25 \\
\hline 28 & 1 & 15 \\
\hline 29 & 2 & 33 \\
\hline 30 & * & 39 \\
\hline 31 & 3 & 35 \\
\hline 32 & 4 & 53 \\
\hline 33 & 2 & 35 \\
\hline 34 & 5 & 25 \\
\hline 35 & 4 & 56 \\
\hline 36 & 1 & 25 \\
\hline 37 & * & 23 \\
\hline
\end{tabular}

Note: $\quad$ Source: Office for National Statistics * Removed due to ONS rules on disclosure.

Table 5

\section{Ratio of MPI to ABI turnover}

\begin{tabular}{lr}
\hline & Ratio MPI/ABI \\
\hline 1999 & 0.82 \\
2000 & 0.83 \\
2001 & 0.84 \\
2002 & 0.85 \\
2003 & 0.83 \\
2004 & 0.85 \\
2005 & 0.76 \\
\hline & Source: Office for National Statistics
\end{tabular}


fuel' (23)). This is consistent with the key finding at an aggregate level, and supports the view that the lower recording of turnover in the MPI is a feature of the unit-level results, rather than associated with sampling or grossing methodology.

At an industrial level, 'food products, beverages' (SIC 15), 'coke, refined petroleum products and nuclear fuel' (23) and 'motor vehicles, trailers and semitrailers' (34) are all systematically underreported in nominal terms. Together, these industries account for over 74 per cent of the total difference.

\section{Correlation and regression analysis}

It is possible to test formally the relationship between log ABI turnover and $\log$ MPI turnover by calculating a correlation coefficient. The Kendall tau rank correlation coefficient ${ }^{3}$ is used to measures the degree to which two variables are linearly related. A positive value indicates that the variables move in the same direction and a negative one in the opposite direction. A correlation coefficient of +1 or -1 means that there is a perfect positive/negative linear relationship; 0 indicates that there is no correlation.

The results of the correlations are presented in Table 6. The table shows that

\section{Table 6}

\section{Kendall tau rank correlation coefficient for $\mathrm{MPI}$ and $\mathrm{ABI}$ turnover returns}

\begin{tabular}{|c|c|c|c|c|c|c|c|}
\hline SIC2 & 1999 & 2000 & 2001 & 2002 & 2003 & 2004 & 2005 \\
\hline 15 & 0.87 & 0.87 & 0.88 & 0.90 & 0.89 & 0.88 & 0.89 \\
\hline 16 & * & * & * & * & * & * & * \\
\hline 17 & 0.81 & 0.81 & 0.79 & 0.82 & 0.83 & 0.86 & 0.87 \\
\hline 18 & 0.83 & 0.79 & 0.81 & 0.83 & 0.79 & 0.84 & 0.85 \\
\hline 19 & 0.72 & 0.76 & 0.75 & 0.83 & 0.80 & 0.81 & 0.84 \\
\hline 20 & 0.86 & 0.80 & 0.78 & 0.82 & 0.82 & 0.88 & 0.87 \\
\hline 21 & 0.89 & 0.88 & 0.88 & 0.89 & 0.88 & 0.87 & 0.87 \\
\hline 22 & 0.82 & 0.85 & 0.85 & 0.85 & 0.87 & 0.84 & 0.87 \\
\hline 23 & * & * & * & * & * & * & * \\
\hline 24 & 0.88 & 0.87 & 0.88 & 0.88 & 0.89 & 0.90 & 0.87 \\
\hline 25 & 0.87 & 0.86 & 0.86 & 0.87 & 0.87 & 0.86 & 0.88 \\
\hline 26 & 0.88 & 0.90 & 0.90 & 0.90 & 0.91 & 0.91 & 0.91 \\
\hline 27 & 0.87 & 0.88 & 0.88 & 0.90 & 0.88 & 0.89 & 0.90 \\
\hline 28 & 0.85 & 0.86 & 0.84 & 0.85 & 0.86 & 0.85 & 0.86 \\
\hline 29 & 0.81 & 0.82 & 0.81 & 0.82 & 0.83 & 0.85 & 0.84 \\
\hline 30 & 0.85 & 0.89 & 0.85 & 0.83 & 0.83 & 0.82 & 0.80 \\
\hline 31 & 0.80 & 0.80 & 0.81 & 0.85 & 0.84 & 0.84 & 0.85 \\
\hline 32 & 0.88 & 0.88 & 0.85 & 0.84 & 0.85 & 0.83 & 0.87 \\
\hline 33 & 0.78 & 0.81 & 0.81 & 0.84 & 0.83 & 0.83 & 0.84 \\
\hline 34 & 0.83 & 0.82 & 0.83 & 0.84 & 0.84 & 0.86 & 0.84 \\
\hline 35 & 0.82 & 0.83 & 0.80 & 0.84 & 0.84 & 0.87 & 0.88 \\
\hline 36 & 0.78 & 0.81 & 0.81 & 0.80 & 0.80 & 0.84 & 0.84 \\
\hline 37 & 0.80 & 0.76 & 0.82 & 0.77 & 0.83 & 0.78 & 0.79 \\
\hline
\end{tabular}

Figure 3

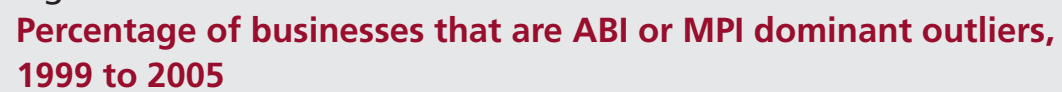

Percentages ${ }^{1}$

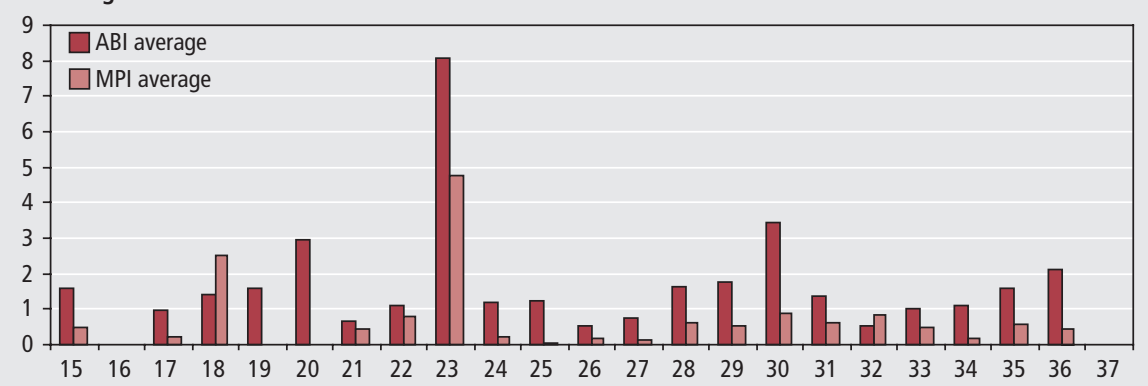

Note:

Source: Office for National Statistics
MPI turnover is highly correlated for all manufacturing industries and is generally improving over time. As such, MPI turnover can be said to be a valid predictor of $\mathrm{ABI}$ turnover.

Quantile regressions were also used as a pseudo-correlation test to test the robustness of the correlations and further evaluate the extent to which two variables are similar. The full results are shown in Appendix Table A3. They confirm that the MPI is generally a good predictor of the $\mathrm{ABI}$ and demonstrate that the centre of the distributions of both ABI and MPI returns are unbiased.
* Removed due to ONS rules on disclosure.

\section{Sensitivity analysis}

In order to explore which industries were most severely affected by individual companies reporting the largest difference in ABI and MPI returns, and the extent to which the results were affected by extreme values, MPI and ABI dominant outliers were constructed. Initially, a $\log$ ratio of MPI and ABI turnover was calculated; Figure 3 plots the proportion of observations that had a log ratio of greater than 0.5 or less than -0.5 (a 50 per cent difference between the two). A ratio of greater than 0.5 indicates an $\mathrm{ABI}$ dominant outlier and a ratio of less than -0.5 identifies an MPI dominant outlier.

There are more ABI-dominant outliers in the majority of industries. These outliers are partially responsible for the evident discrepancy in the levels of the ABI and MPI at the aggregate level. At an industrial level, 'coke, refined petroleum products and nuclear fuel' (SIC 23) had proportionately the largest number of ABI and MPI dominant outliers.

The following analysis looks at the impact of the outliers between the two surveys on the aggregate growth series. For this analysis, a simple weighted methodology is used to produce an MPI-equivalent time series from the microdata. ${ }^{4}$ The same firms are then subtracted from the MPI and $\mathrm{ABI}$ samples and weighted up to examine the aggregate effect of the subtraction of outliers at the 1, 5 and 10 per cent tails of the distribution. These aggregates are then compared to observe what difference eliminating outliers has on the aggregate growth rates.

Figure 4 and Figure 5, respectively, chart the difference in the growth rates for the MPI and ABI microdata excluding outliers. The graphs plot the difference by taking the overall growth rate including all observations and subtracting the growth 


\section{Figure 4 \\ Percentage difference in MPI microdata turnover annual growth rates after excluding outliers}

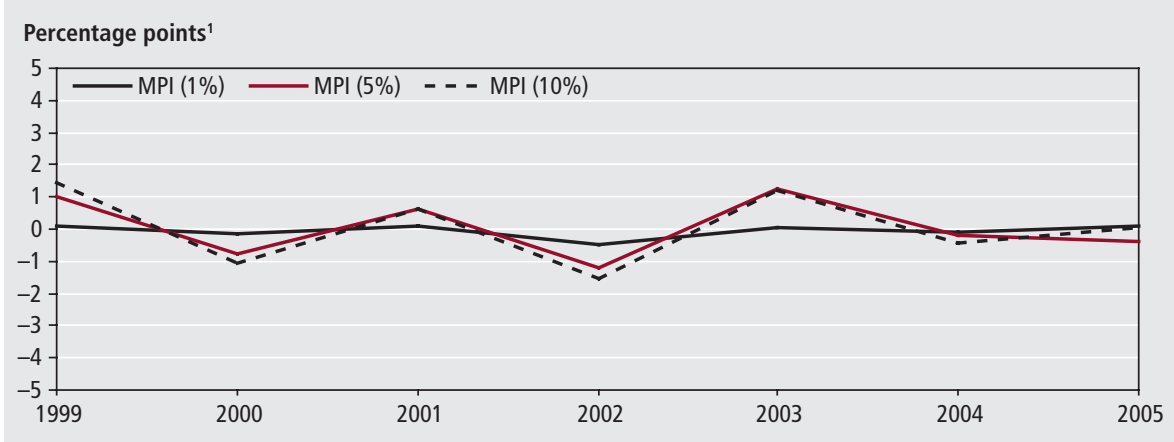

Note:

Source: Office for National Statistics

1 Difference from overall growth rate.

\section{Figure 5}

\section{Percentage difference in $A B I$ microdata turnover annual growth rates after excluding outliers}

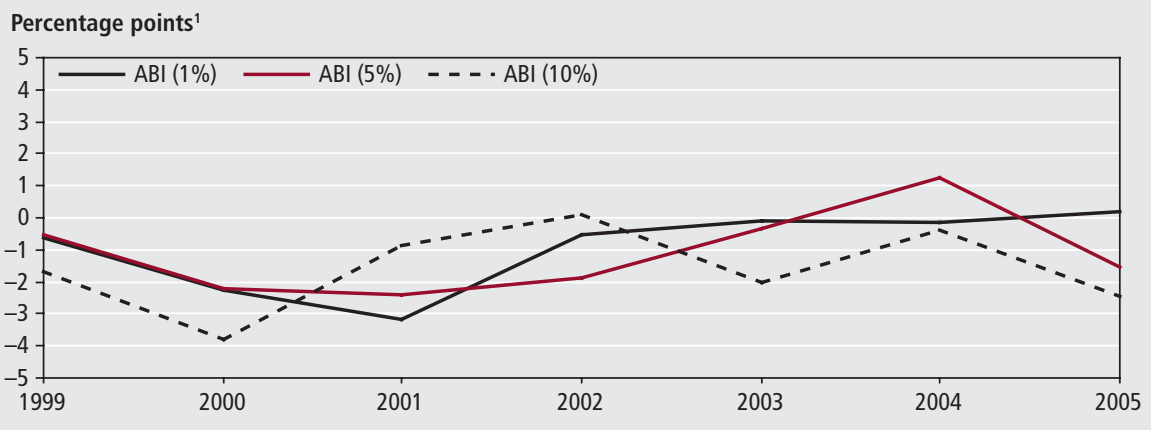

Note:

1 Difference from overall growth rate. rate generated after excluding outliers from the 1,5 and 10 per cent tails. For example, if the difference is zero, this means that omitting outliers has no effect on the overall growth rate.

By comparing Figure 4 and Figure 5, it is clear that the ABI data set was more affected by omitting outliers. Overall, however, omitting outliers from both data sets had relatively little impact on estimating growth rates. In both the MPI and ABI series, there is no evidence of any bias. This suggests that, although some companies may report considerably different turnover values in their MPI and ABI returns, they have relatively little impact on growth rates.

\section{MIDSS results}

\section{Aggregate analysis}

The first strand of the aggregate analysis is to examine whether any bias exists in the levels and growth rates of the total series in both the MIDSS and ABI turnover.

\section{Nominal values}

Table 7 compares the grossed total turnover implied by the MIDSS and ABI aggregate series. It is evident that the $\mathrm{ABI}$ produces that the unadjusted MIDSS series is closer to the $\mathrm{ABI}$ growth rate than the adjusted one.

Figure 7 graphs the difference decomposed into two-digit SICs. The MIDSS industries not explicitly referred to are captured as 'Other'.

The contributions depicted in Figure 7 demonstrate that there is no consistent direction of bias in any industry. SIC 51 (wholesale trade) contributes the largest difference to the ABI and MIDSS growth rate. The wholesale trade data can be considerably influenced by single large companies, particularly those working in commodities such as oil. These companies are generally multinational in nature and as such are exposed to changes in exchange rates. These changes can considerably affect the valuation of output over time.

\section{Noise-to-signal ratio}

As with the MPI analysis, an additional way of quantifying the congruence of two series is the noise-to-signal ratio. Table 8 presents the noise-to-signal ratios for both unadjusted and adjusted growth rates compared with those from the ABI. As described previously, the closer the ratio is to zero, the stronger the statistical signal.

Table 8 shows that the unadjusted MIDSS growth rates contain stronger statistical signals than the adjusted - this is true for the service sector as a whole and the majority of twodigit SIC industries. It is consistent with the aggregate and growth rate analysis reported in Table 7 and Figure 7 , respectively, which showed that the unadjusted MIDSS data were better at tracking the $\mathrm{ABI}$ series. This is also supported from the finding in the MPI section, which reported an improved signal for certain two-digit SIC industries: together, these industries accounted for more than 50 per cent of turnover.

This is an important finding of the article and adds support to ONS's recent $\mathrm{ABI}$. It is also evident from these averages

\section{Table 7}

\section{$\mathrm{ABI}$ and MIDSS aggregate turnover}

\begin{tabular}{lrrrrrr}
\hline & \multicolumn{2}{c}{ Turnover (f million) } & & \multicolumn{2}{c}{ Ratio (MIDSS/ABI) } \\
\cline { 2 - 3 } \cline { 5 - 6 } & ABI & $\begin{array}{r}\text { MIDSS } \\
\text { unadjusted }\end{array}$ & $\begin{array}{r}\text { MIDSS } \\
\text { adjusted }\end{array}$ & & $\begin{array}{r}\text { MIDSS } \\
\text { unadjusted }\end{array}$ & $\begin{array}{r}\text { MIDSS } \\
\text { adjusted }\end{array}$ \\
\hline 1999 & 862,281 & 842,494 & 782,246 & & 0.98 & 0.91 \\
2000 & 925,482 & 911,030 & 848,135 & & 0.98 & 0.92 \\
2001 & 970,158 & 948,385 & 894,417 & & 0.98 & 0.92 \\
2002 & 979,605 & 973,123 & 938,329 & & 0.99 & 0.96 \\
2003 & $1,051,876$ & $1,013,367$ & 987,251 & & 0.96 & 0.94 \\
2005 & $1,109,666$ & $1,064,147$ & $1,056,823$ & & 0.96 & 0.95 \\
\hline
\end{tabular}




\section{Figure 6}

\section{MIDSS and $A B I$ annual turnover growth rates}

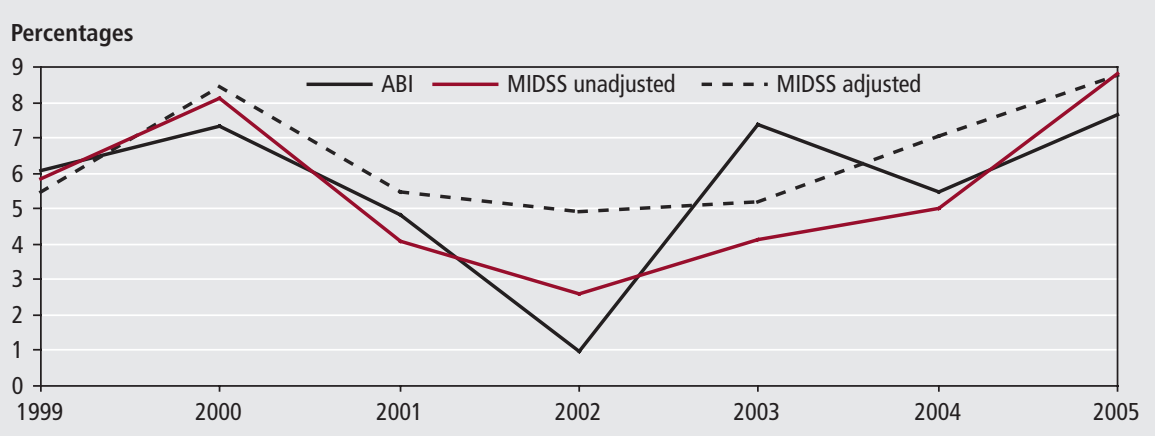

Figure 7

\section{Contributions to differences in ABI and unadjusted MIDSS turnover growth rates}

Percentage points

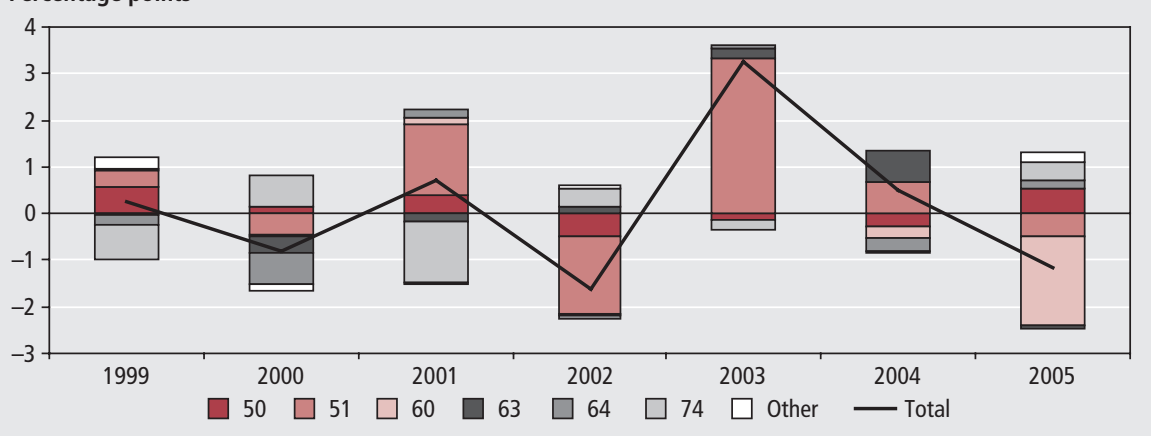

Table 8

Noise-to-signal ratio between the adjusted and unadjusted MIDSS time series and $\mathrm{ABI}$ growth rates, 1999 to 2005

\begin{tabular}{lrr}
\hline SIC2 & Unadjusted & Adjusted \\
\hline 50 & 1.60 & 2.23 \\
51 & 0.20 & 0.41 \\
55 & -0.64 & -0.49 \\
60 & -0.98 & -0.99 \\
63 & -0.87 & -0.83 \\
& & \\
64 & 0.10 & 0.86 \\
71 & -0.60 & -0.58 \\
72 & -0.14 & -0.58 \\
73 & -0.40 & -0.29 \\
74 & 0.03 & -0.61 \\
& & \\
90 & 0.19 & -0.35 \\
92 & -0.20 & 0.16 \\
93 & 0.96 & -0.53 \\
Total & 0.37 & 0.50 \\
\hline
\end{tabular}

Source: Office for National Statistics

decision to substantially remove the MIDSS adjustments for the Index of Services data used in the compilation of the Blue Book 2008.

The next section uses business microdata to further investigate the relationship between ABI and MIDSS returns by analysing individual business responses.

\section{Microdata analysis}

This section examines individual businesses reporting turnover in the MIDSS and ABI surveys, using both correlation and results, all analysis was undertaken using natural logarithms.

For the MIDSS survey, there were fewer companies matched in the microdata set in the years before 2001. This is because new industries were added to the MIDSS survey in recent years. For example, in 2001, there was an improvement in the match between the $\mathrm{ABI}$ and MIDSS data sets when SIC 50, 55, 92 and 93 were introduced. As such, it is only possible to make robust comparisons for the microdata relating to the period 2001 to 2005 .

Table 9 details the frequencies of businesses in the overlap data set in each year. The matched sample accounts for less than 1 per cent of all MIDSS businesses but approximately 15 per cent of all businesses included in the overall matched sample.

Perhaps more important than the business counts, in terms of the sufficiency of the overlap data set for supporting overall conclusions, is the proportion of total employment covered by the matched businesses. Table 10 gives the percentage of employment: this is presented by year, there being some change on an annual basis as the survey changed structure. regression analysis. As with the MPI micro
Table 9

Frequencies of matched businesses in the overlap microdata set

\begin{tabular}{lrr}
\hline & $\begin{array}{r}\text { Frequency } \\
\text { (number) }\end{array}$ & Percentages \\
\hline 2001 & 4,453 & 0.5 \\
2002 & 4,541 & 0.5 \\
2003 & 4,538 & 0.5 \\
2004 & 4,439 & 0.5 \\
2005 & 4,414 & 0.4 \\
Total & 28,473 & 0.4 \\
\hline & Source: Office for National Statistics
\end{tabular}

Although the matched sample has low business coverage, the total employment coverage ranges between 29 and 37 per cent. This is indicative of the fact that it is predominantly larger businesses that are matched between the MIDSS and ABI surveys. The fact that roughly onethird of total employment is covered by the overlap means that inferences about overall trends are possible from this microdata analysis.

\section{Correlation and regression analysis}

Table 11 presents the correlation coefficients. It is evident that businesses in most industries seem to report broadly similar turnover in both surveys. The biggest industries, 51 and 74, have coefficients of around 0.95 . Industries 63 and 73 are the only industries with coefficients consistently under 0.9 , but these represent two of the smaller industries in terms of employment.

Quantile regressions were used to test, and subsequently confirmed, the robustness of the correlation results. The full regression results are reported in Appendix Table A4.

\section{Sensitivity analysis}

This section examines which industries are most affected by companies reporting the largest differences between the two surveys. Figure $\mathbf{8}$ shows the percentage of businesses that are classed as severe outliers.

Figure 8 shows that there is a predominance of larger discrepancies for returns in industries 63, 73 and 92. SIC 73 'Research and development' and 92 'Recreational and sporting activities' also performed poorly in the regression analysis. Industry 63 'Supporting and auxiliary transport activities' performed poorly in the correlation analysis. In general, there are more ABI dominant outliers in most industries, again partially explaining the discrepancy in the levels of ABI and MIDSS at the aggregate level.

The following analysis examines the effect 
Table 10

Percentage of total employment contained in the overlap data set

\begin{tabular}{lrrrrr}
\hline SIC2 & \multicolumn{2}{c}{} & \multicolumn{2}{r}{ Percentages } \\
\hline 50 & 2001 & 2002 & 2003 & 2004 & 2005 \\
51 & 23 & 25 & 28 & 30 & 31 \\
55 & 30 & 28 & 31 & 34 & 34 \\
60 & 16 & 38 & 32 & 33 & 36 \\
63 & 49 & 45 & 47 & 47 & 48 \\
& 45 & 43 & 43 & 54 & 58 \\
64 & 59 & 62 & 63 & & 74 \\
71 & 38 & 34 & 32 & 31 & 35 \\
72 & 23 & 27 & 25 & 28 & 33 \\
73 & 40 & 33 & 30 & 45 & 42 \\
74 & 30 & 31 & 34 & 34 & 35 \\
& & & & & 49 \\
90 & 50 & 46 & 61 & 57 & 25 \\
92 & 27 & 34 & 38 & 35 & 17 \\
93 & 17 & 19 & 18 & 18 & 37 \\
Total & 29 & 34 & 34 & 36 & \\
\hline
\end{tabular}

Source: Office for National Statistics

Table 11

\section{Kendall tau rank correlation coefficients for MIDSS and ABI turnover} returns

\begin{tabular}{lrrrrr}
\hline SIC2 & 2001 & 2002 & 2003 & 2004 & 2005 \\
\hline 50 & 0.94 & 0.92 & 0.95 & 0.95 & 0.95 \\
51 & 0.94 & 0.95 & 0.94 & 0.95 & 0.96 \\
55 & 0.92 & 0.94 & 0.94 & 0.95 & 0.96 \\
60 & 0.94 & 0.96 & 0.98 & 0.96 & 0.95 \\
63 & 0.73 & 0.76 & 0.76 & 0.73 & 0.77 \\
64 & & & & 0.95 \\
71 & 0.95 & 0.94 & 0.94 & 0.97 & 0.94 \\
72 & 0.96 & 0.92 & 0.97 & 0.92 & 0.93 \\
73 & 0.90 & 0.92 & 0.92 & 0.93 & 0.87 \\
74 & 0.81 & 0.74 & 0.84 & 0.84 & 0.95 \\
90 & 0.94 & 0.94 & 0.95 & 0.95 & 0.97 \\
92 & & & & 0.95 \\
93 & 0.97 & 0.93 & 0.96 & 0.95 & 0.95 \\
\hline
\end{tabular}

Source: Office for National Statistics

\section{Figure 8 \\ Percentage of businesses that are ABI or MIDSS dominant outliers, 1999 to 2005}

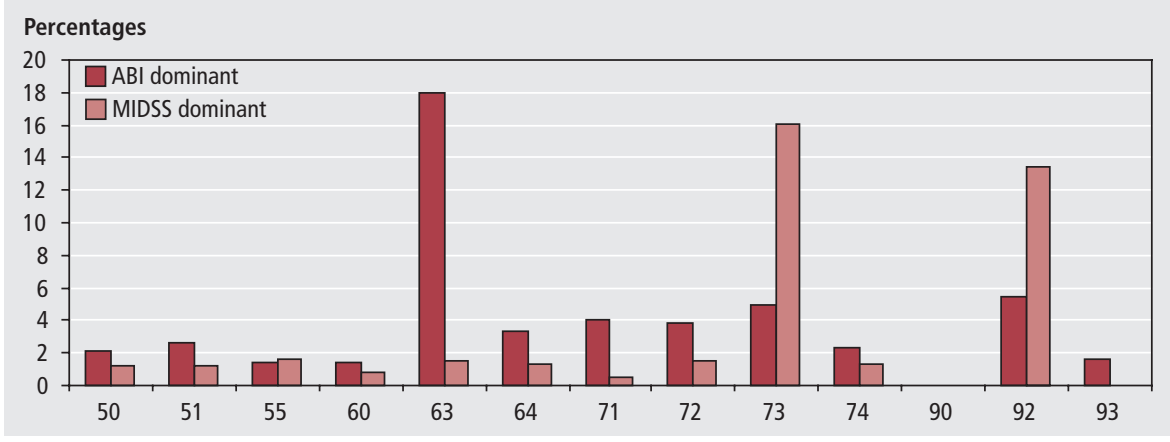

Note:

Source: Office for National Statistics

Results for SIC90 have been removed due to ONS rules on disclosure.

of the outliers between the two surveys on the aggregate series by constructing a time series from the microdata. Figure 9 and

Figure 10 record the difference between the growth rate for the full matched sample and the growth rate after removing the top 1, 5 and 10 per cent of the tails. Figure 9 shows the difference in MIDSS growth rates as the businesses are subtracted; Figure 10 does the same for the ABI.

There is no evidence of any bias in either of the series. By comparing Figure 9 and
Figure 10, it is evident that the ABI data set is more affected by omitting outliers, at least in two of the four data points. However, in general, for both series, there is little change to the aggregate growth rates from taking out the businesses with large outliers. This supports the results of the MPI analysis and implies that, while there may be some businesses reporting very different turnover figures on the two surveys, this has little impact on the growth rates generated from the data.

\section{Conclusion}

For the MPI, the following conclusions can be drawn:

- nominal turnover is consistently underreported in MPI monthly surveys compared with the ABI annual survey. The finding is consistent in both the aggregate and micro analysis

- MPI annual growth rates are closely aligned to $\mathrm{ABI}$ annual growth rates in all years - this is evident in both for the aggregate and microanalysis

- the evidence from the microdata suggests that MPI unadjusted data in a number of industries have greater statistical signal than the adjusted data - therefore it may be more appropriate to use the raw data in a number of cases. This finding will help to inform the nature of the adjustment regime, to ensure that it does not inadvertently introduce bias at the aggregate level

For the MIDSS, the following conclusions can be drawn:

- both MIDSS adjusted and unadjusted time series demonstrate a lower level of turnover than the ABI. The unadjusted series produces a slightly closer level than that including the adjustments

- the MIDSS growth rates are moderately close to the $\mathrm{ABI}$ growth rates for the equivalent service sector industries. There is no consistent bias in either the adjusted or unadjusted series evident in these growth rates

- the stronger statistical signal suggests that the unadjusted MIDSS series is a better indicator of $\mathrm{ABI}$ growth rates than the unadjusted series

- while some businesses report very different turnover figures to the MIDSS and ABI surveys, this has little impact on the growth rates generated from the data

The following joint conclusions can be drawn from the MPI and MIDSS: 


\section{Figure 9 \\ Percentage difference in MIDSS microdata turnover annual growth rates after excluding outliers}

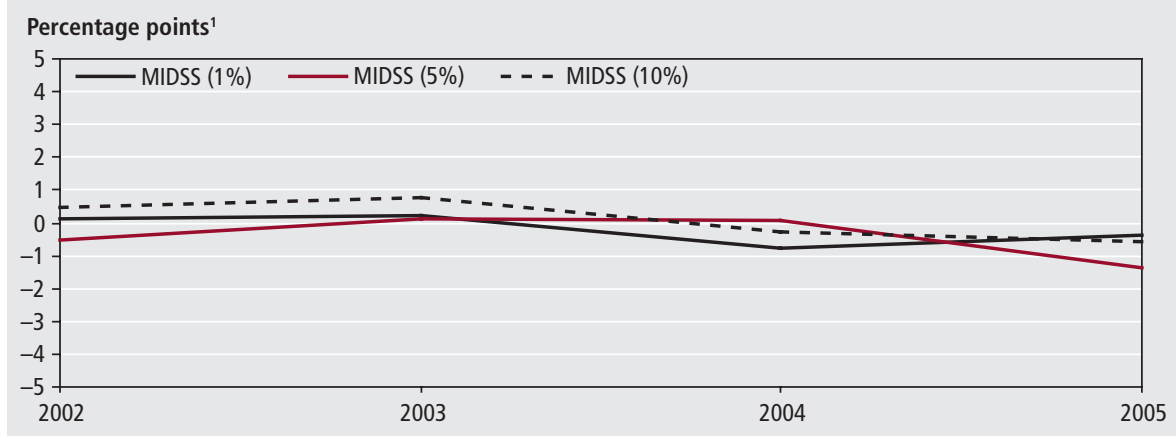

Note:

Source: Office for National Statistics

1 Difference from overall growth rate.

\section{Figure 10}

\section{Percentage difference in $\mathrm{ABI}$ microdata turnover annual growth rates after excluding outliers}

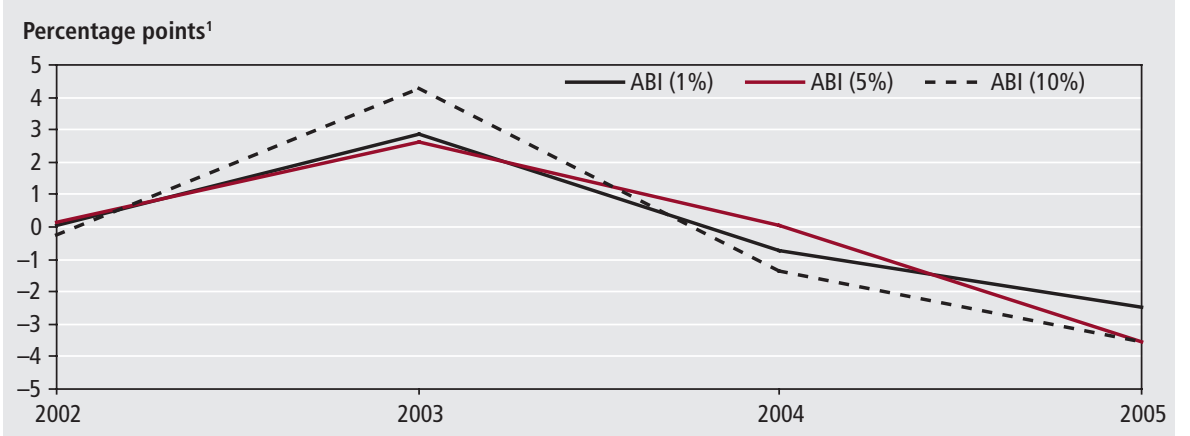

Note:

1 Difference from overall growth rate.

- matching businesses between monthly and annual surveys is feasible and produces a reasonable match, although almost entirely for larger businesses

- both MPI and MIDSS aggregate series do not produce biased growth rates when compared with ABI turnover. However, highlighted industries have been responsible for much of the difference

- businesses are generally good at reporting monthly and annual turnover consistently. There are examples of where this is not the case, but the aggregate impact would appear to be negligible

\section{Notes}

1 GDP can be measured using three separate approaches: production (GVA), income (GDP(I)) and expenditure $(\mathrm{GDP}(\mathrm{E}))$. $\mathrm{GDP}(\mathrm{O})$ is purely an output-based measure, which acts as a proxy for the production approach (GVA) in order to estimate quarterly GDP.

2 The Virtual Microdata Laboratory (VML) is a facility within the Office

\section{ACKNOWLEDGEMENTS}

The authors would like to thank Robin Youll, Felix Ritchie, Tony Clayton, High Skipper, David Hobbs, Sanjiv Mahajan and John Perry, for helpful comments. Any errors are the authors' sole responsibility.

\section{CONTACT}

(《) elmr@ons.gsi.gov.uk

\section{REFERENCES}

Drew S and Morgan D (2007) 'The launch of the Index of Services as a National Statistics', Economic \& Labour Market Review 1(3), pp 39-46 and at

www.statistics.gov.uk/cci/article. $a s p ?$ id $=1741$

Duff S and Morgan D (2007) 'BERR Analysis: MIDSS v ABI Correlation - Early Findings', Office for National Statistics, unpublished. Hobbs D (2008) 'What does 'turnover' mean?' Office for National Statistics, unpublished.

Jones G (2000) 'The Development of the Annual Business Inquiry', Economic Trends 564, pp 49-57 and at www.statistics.gov.uk/cci/article.asp? $\mathrm{id}=74$ Mahajan S (1997) 'Balancing GDP: UK Annual Input-Output Balances', Economic Trends 519.

Mahajan S (2006) 'United Kingdom Input-

Output Analyses, pp 211-59 at

www.statistics.gov.uk/inputoutput

Robinson H (2005) 'Revisions to Quarterly GDP Growth and its Production (Output), Expenditure and Income components', Economic Trends 625, pp 34-49 and at www.statistics.gov.uk/cci/article. asp? $\mathrm{id}=1289$

Smith J, Kelsoe R, Snell M, Wolley K and Drury S (2007) 'ABI2/MPI 2005 Congruence', Office for National Statistics, unpublished.

Taylor C (2004) 'Monthly Production Inquiry Process Documentation', Office for National Statistics, unpublished. 


\section{APPENDIX}

Table A1

\section{MPI industries}

Manufacturing industry SIC (2003)

Food products, beverages

Tobacco

Textiles

Wearing apparel; dressing and dyeing of fur

Tanning and dressing of leather

Wood and of products of wood and cork, except furniture

Pulp, paper and paper products

Publishing, printing and reproduction of recorded media

Coke, refined petroleum products and nuclear fuel

Chemicals and chemical products

Rubber and plastic products

Other non-metallic mineral products

Basic metals

Fabricated metal products, except machinery and equipment

Machinery and equipment not elsewhere classified

Office machinery and computers

Electrical machinery and apparatus not elsewhere classified

Radio, television and communication equipment not elsewhere classified

Medical, precision and optical instruments, watches and clocks

Motor vehicles, trailers and semi-trailers

Other transport equipment

Manufacturing not elsewhere classified

Recycling

Table A2

\section{MIDSS industries}

Distribution and service sectors

Sale, maintenance and repair of motor vehicles

Wholesale trade and commission trade

Hotels and restaurants

Land transport; transport via pipelines

Supporting and auxiliary transport activities

Post and telecommunications

Renting of machinery and equipment

Computer and related activities

Research and development

Other business activities

Sewage and refuse disposal

Recreational, cultural and sporting activities

Extra-territorial organisations and bodies 


\section{Regression}

A regression of a dependent variable upon an identical explanatory variable will yield the result of an intercept term equal to zero and a slope coefficient of one. Consequently, regressing ABI turnover against MPI/MIDSS turnover will produce coefficients close to these values if they are congruent variables. Cells marked with * in Table A3 denote that the values were not equal at a 5 per cent significant level.

\section{Table A3}

$\mathrm{ABI}$ and MPI median regressions where the joint-hypothesis test can be rejected at the 5 per cent significance level

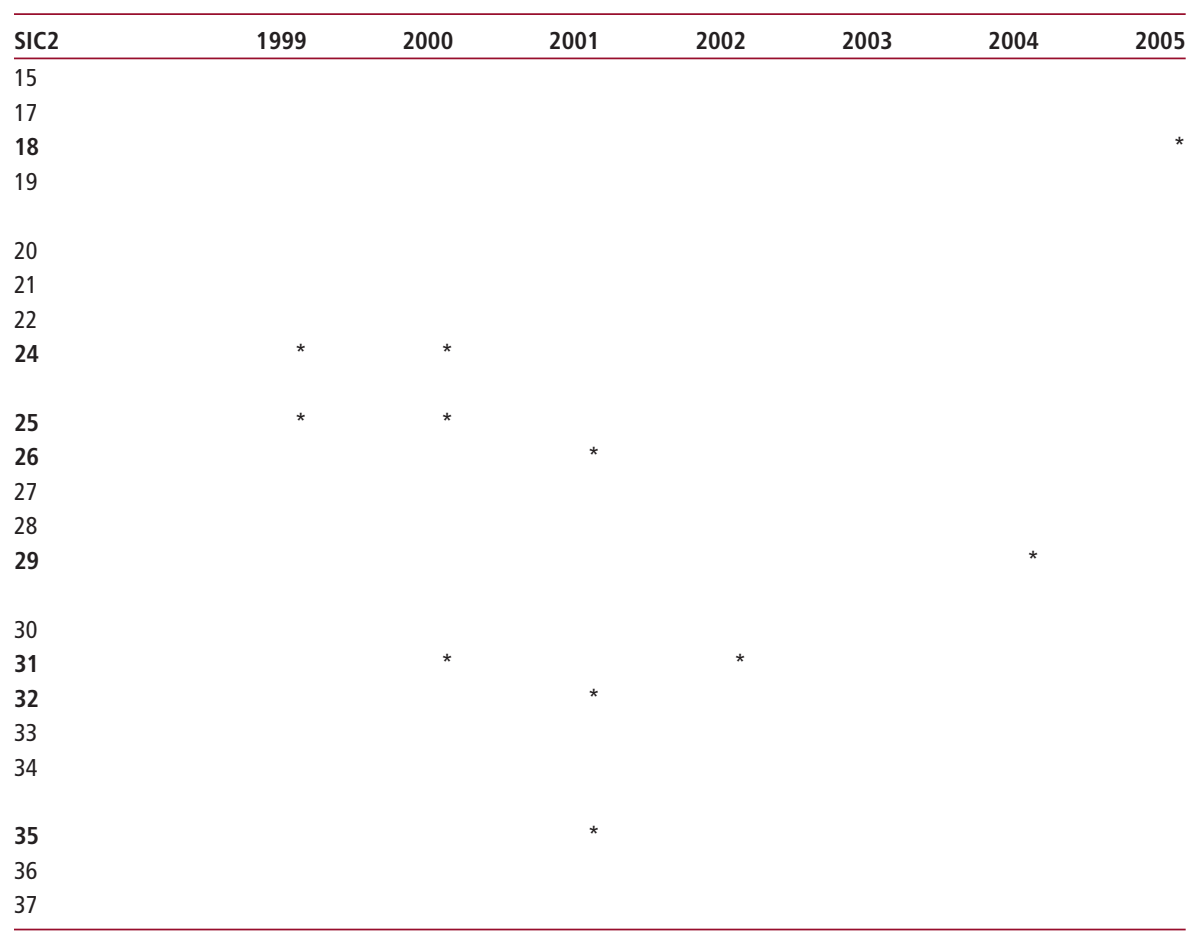

Source: Office for National Statistics

Table A4

$A B I$ and MIDSS median regressions where the joint-hypothesis test can be rejected at the 5 per cent significance level

\begin{tabular}{|c|c|c|c|c|c|}
\hline SIC2 & 2001 & 2002 & 2003 & 2004 & 2005 \\
\hline \multicolumn{6}{|l|}{50} \\
\hline 51 & & & * & & \\
\hline 55 & * & * & * & * & * \\
\hline 60 & * & * & & & * \\
\hline 63 & * & & & & \\
\hline 64 & & & & & * \\
\hline \multicolumn{6}{|l|}{71} \\
\hline \multicolumn{6}{|l|}{72} \\
\hline 73 & * & & * & * & * \\
\hline 74 & & * & * & * & \\
\hline 90 & & * & & * & \\
\hline 92 & * & * & * & * & * \\
\hline 93 & & & & & \\
\hline
\end{tabular}

